\title{
Assessing uncertainties in crop model simulations using daily bias-corrected Regional Circulation Model outputs
}

\author{
Guillermo A. Baigorria ${ }^{1, *}$, James W. Jones ${ }^{1}$, Dong-Wook Shin ${ }^{2}$, Ashok Mishra ${ }^{3}$, \\ James J. O'Brien²
}

\begin{abstract}
${ }^{1}$ Agricultural \& Biological Engineering Department, University of Florida, Gainesville, Florida 32611-0570, USA
${ }^{2}$ Center for Ocean-Atmospheric Prediction Studies, The Florida State University, Tallahassee, Florida 32312, USA

${ }^{3}$ International Research Institute for Climate and Society, The Earth Institute at Columbia University, Palisades, New York 10964, USA
\end{abstract}

\begin{abstract}
Outputs from the Florida State University/Center for Ocean-Atmospheric Prediction Studies (FSU/COAPS) regional spectral model were linked to the CERES-Maize dynamic crop model, and the sources of uncertainty in yield prediction at 3 sites in the southeastern USA were examined. Daily incoming solar radiation, Tmax and Tmin, and rainfall output data were obtained from 1987 to 2004 of retrospective forecasts (hindcasts) that contained 20 ensemble members. These raw hindcasts were bias-corrected on their cumulative probability functions by using the historical daily weather records prior to the $18 \mathrm{yr}$ hindcasted period. Six combinations of the 4 meteorological variables from raw and bias-corrected hindcasts and climatological values were used as sets of weather inputs into the CERES-Maize crop model. Uncertainties related to these combinations of sets of weather inputs were analyzed. The bias-correction method improved values of monthly statistics of the ensemble compared to the raw hindcasts in relation to the observed data. The number and length of dry spells were also made more accurate with this correction. The main source of uncertainty in linking the FSU/COAPS climate model to the CERES-Maize crop model was the specific timing of the occurrence of dry spells during the cropping seasons. Plant growth stress caused by soil water deficit during crucial phenological states largely affects simulated yields. Operationally, the inability of FSU/COAPS to accurately predict the timing of the occurrence of dry spells makes its climate forecasts less useful for farmers wishing to optimize planting dates and crop varieties for crops with short crucial phenological phases, such as maize.
\end{abstract}

KEY WORDS: Crop yield forecasts · Regional circulation models $\cdot$ Crop models $\cdot$ Bias correction · Seasonal climate forecasts Resale or republication not permitted without written consent of the publisher

\section{INTRODUCTION}

Agricultural and related stakeholders are greatly affected by the interannual variability of the climate. Highresolution forecasts produced by numerical climate models may provide useful data for agricultural decision makers. Important crop decisions are made at the beginning of the cropping season. These decisions (such as what, how, and when to plant) are usually based on historical climate and crop data (Hansen 2002, Jagtap et al.
2002), and they cannot be easily changed during the cropping season (Jones et al. 2000, Baigorria 2007). Dynamic crop models have been used in the last decade as supporting tools for decision makers by evaluating possible scenarios of interannual climate variability (e.g. Hansen \& Indeje 2004) and climate change (e.g. Dubrovský et al. 2000) with agriculture. The El Niño-Southern Oscillation (ENSO) index has played an important role in predicting crop yields in many regions of the world (e.g. Podestá et al. 2002). However, seasonal ENSO effects do 
not always coincide with important cropping seasons (Hansen et al. 1999); therefore ENSO does not always have a clear effect on crop yields, especially during summers in the northern hemisphere. Regional Circulation Models (RCMs) nested within Global Circulation Models (GCMs) have the potential to improve forecasts because they predict large-scale circulation patterns that may influence local meteorological variables relative to ENSO-phase alone. In the southeastern United States (SE-USA) there is a weak predictability associated with ENSO during the boreal summer growing season (e.g. Saravanan \& Chang 2000, Giannini et al. 2001). Our hypothesis is that the use of seasonal climate forecasts from an RCM in the SE-USA will produce more reliable predictions of crop yields when coupled with a dynamic crop model. However, it is necessary to understand the uncertainties relating to: (1) the spatial downscaling of the daily seasonal climate forecast; and (2) the integration effect of the crop model with seasonal climate forecasts treated as daily weather sequences.

The Florida State University/Center for OceanAtmospheric Prediction Studies regional spectral model (FSU/COAPS; Cocke \& LaRow 2000, Shin et al. 2006), coupled to the National Center for Atmospheric Research (NCAR) Community Land Model v.2 (CLM2; Bonnan et al. 2002), may generate useful climate forecasts for Alabama, Florida and Georgia. This coupled model (FSU/COAPS) improves the horizontal resolution of the seasonal surface climate outputs from $\sim 200 \mathrm{~km}$ (global model) to $\sim 20 \mathrm{~km}$ (Shin et al. 2005, 2006). Two previously validated convective schemes were included in the model to improve the simulation of seasonal rainfall in the region (Shin et al. 2003): (1) The simplified Arakawa-Shubert scheme (SAS; Pan \& Wu 1994) from the National Center for Environmental Prediction; and (2) the relaxed Arakawa-Shubert scheme (RAS; Rosmond 1992) developed in the Naval Research Laboratory. Detailed information on the convective scheme evaluation in the FSU/COAPS model can be found in Shin et al. (2003).

Over land surfaces, a GCM grid-cell value generally represents the spatial average of several values corresponding to different climatic zones. This fact, in combination with imperfect model specification (e.g. Mearns et al. 1995, Goddard et al. 2001), often causes GCMs to overestimate the number of rainfall events. Hence, the FSU/COAPS model creates shorter dry spells in comparison to the observed data during the simulated cropping season (Shin et al. 2006). This characteristic leads to an under-prediction of water stress and an over-prediction of yields, thus reducing the interannual variability of yields (Dubrovský et al. 2000). Ines \& Hansen (2006) proposed a method to correct biases in rainfall events and amounts applied to the cumulative probability functions (CPF). This method adjusts the CPFs of hindcasted daily rainfall to the CPFs of the historical record. Biases in hindcasted incoming solar radiation and Tmax and Tmin from the FSU/COAPS model were reported by Shin et al. (2006). We extended the bias correction of Ines \& Hansen (2006) to solve this reported problem.

Several studies link GCMs/RCMs to crop models (Hansen \& Indeje 2004, Cantelaube \& Terres 2005, Challinor et al. 2005, Shin et al. 2006, Baigorria 2007). All these studies measured crop yield predictability skills and used different techniques to integrate the forecasted crop yield realizations as probability distributions, but none investigated the uncertainty of yield predictability due to linkage of numerical climate and dynamic crop models-independent methodologies that have been evolving in parallel.

The present study examined several questions related to the linkage of daily hindcast data from a regional climate model to a crop model:

- How much uncertainty is associated with predicting crop yields by feeding crop models with daily FSU/COAPS hindcast data of incoming solar radiation, Tmax and Tmin and rainfall?

- How much uncertainty in crop yield forecasts is associated with each hindcast variable?

- Can daily climate forecast outputs be used as seasonal daily weather sequence forecasts?

Specific objectives of the present study were:

(1) to quantify improvements in skill when bias corrections were applied to daily hindcasts of the 4 selected meteorological variables; and

(2) to find and quantify the uncertainty originating from raw and bias-corrected hindcasts from the FSU/ COAPS when used in a dynamic crop model.

We made no attempt to predict observed corn yields in the SE-USA. Available statistics of crop yield data have their own uncertainties due to spatial (climate and soil variability), temporal (seasonal timescales such as planting dates and crop management timing) and other factors more related to farmer and market preferences (crop variety and management). We will examine uncertainties related to spatial aggregation in future research. In the present study, we focused on the model linking process while trying to fit the crop model outcomes using observed weather data. This assumed that the crop model is a perfect representation of a cornfield.

\section{DATA AND METHODS}

\subsection{Study area}

The study area consists of the states of Alabama, Florida and Georgia in the SE-USA between $35^{\circ} 23^{\prime} \mathrm{N}$, 
$88^{\circ} 59^{\prime} \mathrm{W}$ and $24^{\circ} 57^{\prime} \mathrm{N}, 79^{\circ} 26^{\prime} \mathrm{W}$. This region has some of the warmest climate conditions in the United States. The annual rainfall ranges from 1100 to $1400 \mathrm{~mm}$, with the highest annual precipitation occurring along the Gulf of Mexico coast and in south Florida (USGS 2006). Rainfall occurs throughout the year and is caused by 2 different processes. During most of the fall and winter months, rainfall occurs mainly by fronts coming from the northwestern USA. During this frontal rainy season, correlations among rainfall measured at weather stations are characterized by a widely spread pattern in a northeast-southwest direction, perpendicular to the usual weather front paths. During most of the spring and summer months, rainfall occurs mainly by convective processes and tropical storms. During this convective rainy season, correlations among rainfall measured at weather stations are characterized by small concentric patterns in which correlations decrease rapidly over short distances from each weather station (Baigorria et al. 2007).

Three counties in the study area with available weather and soil data, and where corn has been consistently cultivated during the last $18 \mathrm{yr}$, were selected for the present study. The counties were Alachua (Florida), De Kalb (Alabama) and Tift (Georgia).

\subsection{Data and tools}

\subsubsection{Weather stations}

One weather station from each of the selected counties was used in this study: Gainesville in Alachua County $\left(29^{\circ} 42^{\prime} \mathrm{N}, 82^{\circ} 17^{\prime} \mathrm{W}, 38 \mathrm{~m}\right.$ above sea level [a.s.1.]), Crossville in De Kalb County (34 $17^{\prime} \mathrm{N}$, $85^{\circ} 58^{\prime} \mathrm{W}, 364 \mathrm{~m}$ a.s.l.), and Tifton in Tift County $\left(31^{\circ} 27^{\prime} \mathrm{N}, 83^{\circ} 29^{\prime} \mathrm{W}, 116 \mathrm{~m}\right.$ a.s.l.). All the available daily historical record of Tmax and Tmin and rainfall from these weather stations were obtained from the National Climate Data Center (www.ncdc.noaa.gov/ oa/ncdc.html). Incoming solar radiation was estimated using the technique of Richardson \& Wright (1984).

Because the bias-correction method is based on fitted probability distribution functions for each meteorological variable (Beta distribution for incoming solar radiation, Gaussian distribution for temperatures, and 2-parameter Gamma distribution for rainfall), the chisquared test $\left(\chi^{2}\right)$ was used as a formal quantitative test of the goodness-of-fit. The respective null hypotheses that the observed data were drawn from a fitted hypothetical distribution were not rejected even at the $5 \%$ level in all months, weather stations and meteorological variables.

\subsubsection{Retrospective forecast data (hindcasts)}

Daily hindcasts of incoming solar radiation, Tmax and Tmin, and rainfall were taken individually from 20 ensemble members of the FSU/COAPS regional spectral model (about $20 \mathrm{~km}$ resolution). The hindcast outputs corresponded to the $18 \mathrm{yr}$ period from 1987 to 2004, between March and September of each year. A set of 20 ensemble members was generated from the combinations of 10 different atmospheric initial conditions and 2 convective schemes (SAS and RAS). The seasonal climate simulation outcomes used in this study are not true hindcasts because the FSU/COAPS model uses prescribed weekly sea surface temperatures as input. Each ensemble member is a deterministic hindcast; however the complete ensemble was made to fit a probabilistic hindcast.

\subsubsection{Soil data}

Soil profile characteristics for crop simulations were obtained from the Natural Resources Conservation Service (www.nrcs.usda.gov). The soil in Crossville was characterized by silt loam soil $1.8 \mathrm{~m}$ in depth, in Tifton by loamy sand $2.0 \mathrm{~m}$ in depth, and in Gainesville by sandy soil $2.5 \mathrm{~m}$ in depth. The highest field capacity, which is the maximum amount of water soil can hold against the force of gravity, was for the Crossville soil $\left(0.244 \mathrm{~cm}^{3} \mathrm{~cm}^{-3}\right)$ followed by Tifton $\left(0.183 \mathrm{~cm}^{3} \mathrm{~cm}^{-3}\right)$ and Gainesville $\left(0.103 \mathrm{~cm}^{3} \mathrm{~cm}^{-3}\right)$. Soil organic carbon content followed the same trend among locations with 15.3, 11.4 and $5.7 \mathrm{~g} \mathrm{~kg}^{-1}$ respectively.

\subsubsection{Crop model}

The CERES-Maize model (Jones \& Kiniry 1986) was chosen because of the economic importance of corn in the region and because this crop is more sensitive to soil moisture deficit than other crops in the region, such as cotton and peanuts (Sadras \& Calviño 2001). Thus, impacts of rainfall forecasts on crop yields can be evaluated relative to impacts of total rainfall and rainfall frequency. The CERES-Maize model has been calibrated and validated in different regions of the world (e.g. Steele et al. 2000, Fraisse et al. 2001, Jones et al. 2003), and used for studying impacts of climate variability and change in several regions (e.g. Phillips et al. 1999, Dubrovský et al. 2000, SRAT 2002, Hansen \& Indeje 2004).

The CERES-Maize model was used to simulate corn yield response under the different observed and hindcasted weather data sets. With the exception of the planting date, crop management was set according to 
previous research in Gainesville (Jones et al. 1986). The corn variety simulated was McCurdy 84AA, planted in a density of 7.2 plants $\mathrm{m}^{-2}$. Seven planting dates beginning on March 20 and finishing on May 19 (every 10 d) were simulated for each year. The planting date range was in agreement with standard planting dates in the southeastern USA, though early and late planting dates were constrained due to the hindcast period available. Harvests were set at physiological maturity. The corn crops were simulated as rainfed (no irrigation) and with a total of $255 \mathrm{~kg} \mathrm{ha}^{-1}$ of $\mathrm{N}$ fertilization; $51 \mathrm{~kg} \mathrm{ha}^{-1}$ applied 5 times at $14 \mathrm{~d}$ intervals.

\subsection{Bias correction}

To correct the $18 \mathrm{yr}$ period of daily rainfall amount and frequency of each hindcast's ensemble member, a bias-correction method was applied to the 2-parameter Gamma CPF (Ines \& Hansen 2006). Thus, at the weather station, the CPF of each hindcasted ensemble member was adjusted to the CPF made from the available historical record prior to 1987 (an independent dataset). We extended this method to correct biases on incoming solar radiation, and Tmin and Tmax using the Beta and Gaussian cumulative probability distributions, respectively. The mathematical formulations used to bias-correct incoming solar radiation and temperatures are given in Appendix 1. The bias-correction method was applied to each ensemble member for each month from March to September across the 18 yr period.

\subsection{Measuring bias-correction performance}

\subsubsection{Incoming solar radiation and temperatures}

The total squared error (TSE) was used as an accuracy measurement to compare the cumulative probabilities of the raw and subsequently the bias-corrected hindcast $[F(x)]$, in relation to the observed cumulative probability $\left[F_{0}(x)\right]$ of the evaluated variable $x$ (see Eq. 1). TSE was used to evaluate incoming solar radiation, Tmax and Tmin. To do so, we integrated the areas between the observed and hindcasted curves across the range of cumulative probabilities and variable values.

$$
\operatorname{TSE}=\int_{-\infty}^{+\infty}\left[F(x)-F_{0}(x)\right]^{2} \mathrm{~d} x
$$

\subsubsection{Rainfall}

\subsubsection{Daily rainfall occurrence events}

To evaluate the performance of the bias-correction method on the daily rainfall occurrence events in com- parison to the observed data, $2 \times 2$ contingence tables were used. Contingence tables were performed individually for each ensemble member and for the entire season. Four possibilities were evaluated in the contingence tables: (1) hits: a rainfall event was hindcast and an event occurred; (2) false alarms: a rainfall event was hindcast but a rainfall event did not occur; (3) misses: a rainfall event was not hindcast but a rainfall event occurred; and (4) correct rejections: a rainfall event was not hindcast and an event did not occur. The Peirce skill score (PSS; Peirce 1884) was used to summarize the square contingency tables. The PSS was interpreted as an improvement over a reference forecast, which in this case corresponds to the climatology. The PSS was calculated for each ensemble (i) as:

$\operatorname{PSS}=\frac{p\left(y_{1}, o_{1}\right)+p\left(y_{2}, o_{2}\right)-p\left(y_{1}\right) p\left(o_{1}\right)-p\left(y_{2}\right) p\left(o_{2}\right)}{1-p\left(o_{1}\right) p\left(o_{1}\right)-p\left(o_{2}\right) p\left(o_{2}\right)}$

Variables are defined in Table 1. Perfect forecasts received a score of 1 , random forecasts received a score of 0 , and forecasts inferior to the random forecasts received a negative score (Wilks 2006).

Table 1. Description of variables

\begin{tabular}{|c|c|c|}
\hline Symbol & Definition & Units \\
\hline$x$ & Daily value & $\mathrm{MJ} \mathrm{m}^{-2} \mathrm{~d}^{-1},{ }^{\circ} \mathrm{C}$ \\
\hline $\bar{X}$ & Mean & $\mathrm{MJ} \mathrm{m}^{-2} \mathrm{~d}^{-1}$ or ${ }^{\circ} \mathrm{C}$ \\
\hline$n$ & Sample size & Dimensionless \\
\hline$p, q$ & $\begin{array}{l}\text { Parameters of the } \\
\text { Beta distribution }\end{array}$ & Dimensionless \\
\hline$s$ & Standard deviation & \\
\hline$a, b$ & $\begin{array}{l}\text { Minimum and maximum } \\
\text { possible values of incoming } \\
\text { solar radiation to truncate } \\
\text { the Beta distribution to the } \\
\text { range }[0,1]\end{array}$ & $M J m^{-2} d^{-1}$ \\
\hline$x^{\prime}$ & Transformed value & $\mathrm{MJ} \mathrm{m}^{-2} \mathrm{~d}^{-1}$ \\
\hline$\Gamma$ & $\begin{array}{l}\text { Incomplete Gamma } \\
\text { distribution }\end{array}$ & Dimensionless \\
\hline$X_{i}$ & Monthly hindcasted value & $\mathrm{MJ} \mathrm{m}^{-2} \mathrm{mo}^{-1},{ }^{\circ} \mathrm{C}$ \\
\hline$X_{\text {obs }}$ & $\begin{array}{l}\text { Monthly observed value at } \\
\text { weather station }\end{array}$ & $\mathrm{mm} \mathrm{mo}^{-1}$ \\
\hline $\bar{X}_{\mathrm{obs}}$ & $\begin{array}{l}\text { Monthly observed mean } \\
\text { value at weather station }\end{array}$ & $\mathrm{MJ} \mathrm{m}^{-2} \mathrm{mo}^{-1},{ }^{\circ} \mathrm{C}$ \\
\hline $\bar{X}_{\mathrm{cli}}$ & $\begin{array}{l}\text { Monthly observed climato- } \\
\text { logical value }\end{array}$ & $\mathrm{mm} \mathrm{mo}^{-1}$ \\
\hline$p\left(y_{1}, o_{1}\right)$ & Joint probability of hits & Dimensionless \\
\hline$p\left(y_{2}, o_{2}\right)$ & $\begin{array}{l}\text { Joint probability of correct } \\
\text { rejections }\end{array}$ & Dimensionless \\
\hline$p\left(o_{i}\right)$ & $\begin{array}{l}\text { Marginal distributions of } \\
\text { observations }\end{array}$ & Dimensionless \\
\hline$p\left(y_{i}\right)$ & $\begin{array}{l}\text { Marginal distributions of } \\
\text { forecasts }\end{array}$ & Dimensionless \\
\hline$F(x), F_{0}(x)$ & $\begin{array}{l}\text { Cumulative probability of a } \\
\text { hindcasted (raw or corrected) } \\
\text { and observed variable, } \\
\text { respectively }\end{array}$ & Dimensionless \\
\hline
\end{tabular}




\subsubsection{Monthly rainfall and the number of rainy days}

To evaluate the performance of the bias-correction method on total monthly rainfall amounts and the number of rainy days, mean and standard deviation across the $18 \mathrm{yr}$ hindcast period were calculated individually for each ensemble member. These statistics were calculated for both the raw and the bias-corrected hindcasts, and were compared to the observed data. Root mean squared deviations (RMSD) were calculated monthly and for the entire period from March to September for each ensemble member.

A skill score $\mathrm{SS}_{\mathrm{cli}}(\%)$, constructed using the mean squared error as the accuracy statistic, was used. The $\mathrm{SS}_{\text {cli }}$ was computed using climatological values as the reference forecast, and thus is the percentage improvement over climatology (Wilks 2006). SS $_{\text {cli }}$ values range between $-\infty$ (total lack of predictability in comparison to the climatology) and $+100 \%$ (maximum predictability in relation to the climatology). The $\mathrm{SS}_{\mathrm{cli}}$ was calculated monthly and for the entire period from March to September for each ensemble member (i) (variables defined in Table 1):

$$
\mathrm{SS}_{\mathrm{cli}_{\mathrm{i}}}=100-\frac{\sum\left(X_{i}-\bar{X}_{\mathrm{obs}}\right)^{2}}{\sum\left(X_{\mathrm{obs}}-\bar{X}_{\mathrm{cli}}\right)^{2}} \times 100
$$

\subsubsection{Dry spell length frequencies}

Dry spell length frequencies for the entire period from March to September were calculated for each ensemble member for both the raw and the biascorrected data. Histograms were performed to compare these outcomes with the observed dry spell length frequencies.

\subsection{Linking crop models and RCM}

\subsubsection{Effects of bias-correcting meteorological variables}

Six combinations of the 4 meteorological variables from raw and bias-corrected hindcasts, and climatological values, were used as sets of weather inputs to the crop model: (1) raw hindcasts of all variables; (2) a bias-corrected hindcast of incoming solar radiation and a raw hindcast of the remaining variables; (3) a bias-corrected hindcast of Tmax and Tmin and a raw hindcast of the remaining variables; (4) a biascorrected hindcast of rainfall and a raw hindcast of the remaining variables; (5) a bias-corrected hindcast of rainfall and climatological monthly average of the remaining variables; and (6) a bias-corrected hindcast of all variables.
Each crop simulation used a single set of weather inputs, as well as soil profile and management practices. We did not evaluate how representative the scenarios were, and did not attempt to account for heterogeneity of soils or weather.

After crop simulations for all ensemble members were performed, yearly simulated grain yield dry matter was evaluated to measure the uncertainty of using the 6 different sets of weather inputs. Pearson's correlation and RMSD were computed for simulations using each set of weather inputs based on comparisons with the simulation using observed weather data. The interannual variability of dry matter yields for the entire ensemble was analyzed for each set of weather inputs using box-whisker plots.

\subsubsection{Effects of rainfall distribution}

The CERES-Maize model considers 2 types of zeroto-unity soil water deficit factors (0 indicates no stress, and 1 indicates maximum stress). The factor selected for the present study was the most sensitive, affecting not only photosynthesis but also plant cell expansion (growth). This soil water deficit factor is defined as the ratio between the potential root water uptake from the soil profile and the plant evaporation, multiplied by 0.67 (Jones \& Kiniry 1986).

Analyses of the effects of the quantity and distribution of daily rainfall on the crop simulations were performed seasonally using this water stress factor. Daily values of water stress were transformed to binary data by assigning 1 to all values $>0$ and leaving the remaining values as 0 . Thus, the distribution of the days where water deficit affected growth and yield were taken into account. This was done to analyze the temporal relationship between dry spell distributions and crop yields.

\subsubsection{Simulated crop yield using observed data}

The use of only one planting date to measure the effects of hindcasted daily seasonal climate on crop yields would cause the results to be highly affected by the rainfall distribution relative to the one crop growing cycle (see Section 3.2.2). Analysis across several planting dates reduces the effects of water stress in the crop due to the daily distribution, and emphasizes the interannual variability of the total amount of hindcasted rainfall and the other 3 meteorological variables.

Bias correction applied to all meteorological variables was used to analyze the interannual variability of the potential predictability of corn across the differ- 
ent planting dates. The mean of the 20 crop yield ensemble members over all planting dates was calculated for each year. All grain dry-yield values below $0.5 \mathrm{Mg} \mathrm{ha}^{-1}$ were discarded from the analysis because under real conditions these values would be reached when freezing events occur. Under these circumstances, farmers would partially or totally re-plant their fields depending on the extent of damage. The first quartile, the median, and the third quartile were calculated yearly across the planting dates for both simulations, using observed and hindcasted daily seasonal climate data. Pearson's correlation, along with its statistical significance level and RMSD, were calculated by comparing the averages of both simulated grain dry yields.

\section{RESULTS AND DISCUSSION}

\subsection{Bias correction analysis}

\subsubsection{Incoming solar radiation and temperature}

Comparing the TSE values obtained from the daily raw and bias-corrected hindcasts, it was obvious that the bias-correction of incoming solar radiation and Tmin reduced the values of TSE for the 3 weather stations. However, the bias-correction applied to Tmax in Gainesville was not significant. The same analyses performed at a monthly level showed that the biascorrection for both temperatures were also not significant when applied in Gainesville. This lack of improvement was a result of good skill levels of predictions of these variables in that location by the FSU/ COAPS regional spectral model (Fig. 1).

\subsubsection{Rainfall}

\subsubsection{Daily rainfall events}

As expected, PSS values demonstrated that daily rainfall occurrences were poorly hindcasted. After bias-correcting daily rainfall occurrence events, $68 \%$ of the PSS values were positive; however values were $<0.082$, therefore predictions were only slightly better than a random forecast. These results are not surprising because GCMs and RCMs were created to generate seasonal-climate forecasts and they are not accurate daily weather forecasters, despite the simulation time at which they operate. However, we used bias-corrected daily RCM outputs in dynamic crop models in this study, and the significance of this will be examined further in Section 3.2 .2 .

\subsubsection{Monthly rainfall and the number of rainy days}

Bias correction effectively decreased the number of monthly rainfall events by applying a threshold to achieve the historical record distribution (Ines \& Hansen 2006). Adjustments to the CPF resulted in good performance relative to correctly producing rainfall amounts across the studied months and to the entire season in comparison to the historical record. Over all ensembles, monthly and seasonal biascorrected rainfall amounts averaged for the $18 \mathrm{yr}$ period showed values similar to the climatology. Standard deviations from the historical record were, in $83 \%$ of the cases, lower than those calculated from each ensemble member for the $18 \mathrm{yr}$ period. Similar means and standard deviations that were higher than the climatology were due to the accumulation of monthly rainfall overestimations across the $18 \mathrm{yr}$ period. For the entire season, RMSD within the biascorrected ensemble ranged from 28.2 to $70.0 \%$ of the observed mean rainfall, and from 10.5 to $39.0 \%$ of the observed mean number of rainy days. This was a significant improvement in comparison to the RMSD within the raw ensemble, which ranged from 77.0 to $197.1 \%$ of the observed mean rainfall, and from 63.0 to $196.4 \%$ of the observed mean number of rainy days. Despite the improvements in the hindcasts, $\mathrm{SS}_{\mathrm{cli}}$ showed negative values in most of the cases. Positive values were lower than $8 \%$ for the total rainfall amount, and lower than $5 \%$ for the number of rainy days, taking into account the 3 weather stations and the 20 ensemble members. This means that only in some cases did the bias-corrected hindcast perform better than the climatology. However, improvements in some individual ensemble members increased the predictability skills of the entire probabilistic ensemble.

\subsubsection{Dry spell length frequencies}

The length and frequency of the dry spells were adjusted adequately for the 3 weather stations using the bias corrections. An example for Gainesville for 2 different ensemble members is shown in Fig. 2. Similar results were obtained for all of the ensemble members and weather stations.

\subsection{Linking FSU/COAPS and CERES-Maize models}

\subsubsection{Effects of bias-correcting meteorological variable}

A case study in which only one planting date was used (Fig. 3) shows the comparison of simulated corn yields using the raw hindcasts of all variables (Fig. 3a) versus 
Gainesville
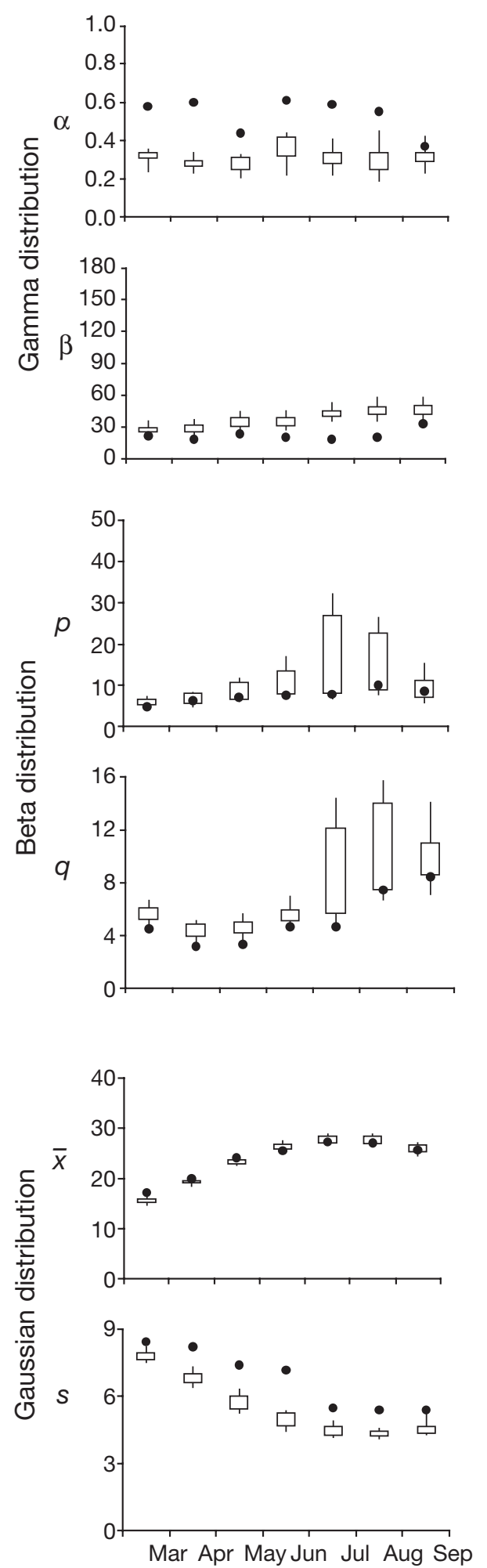

Crossville
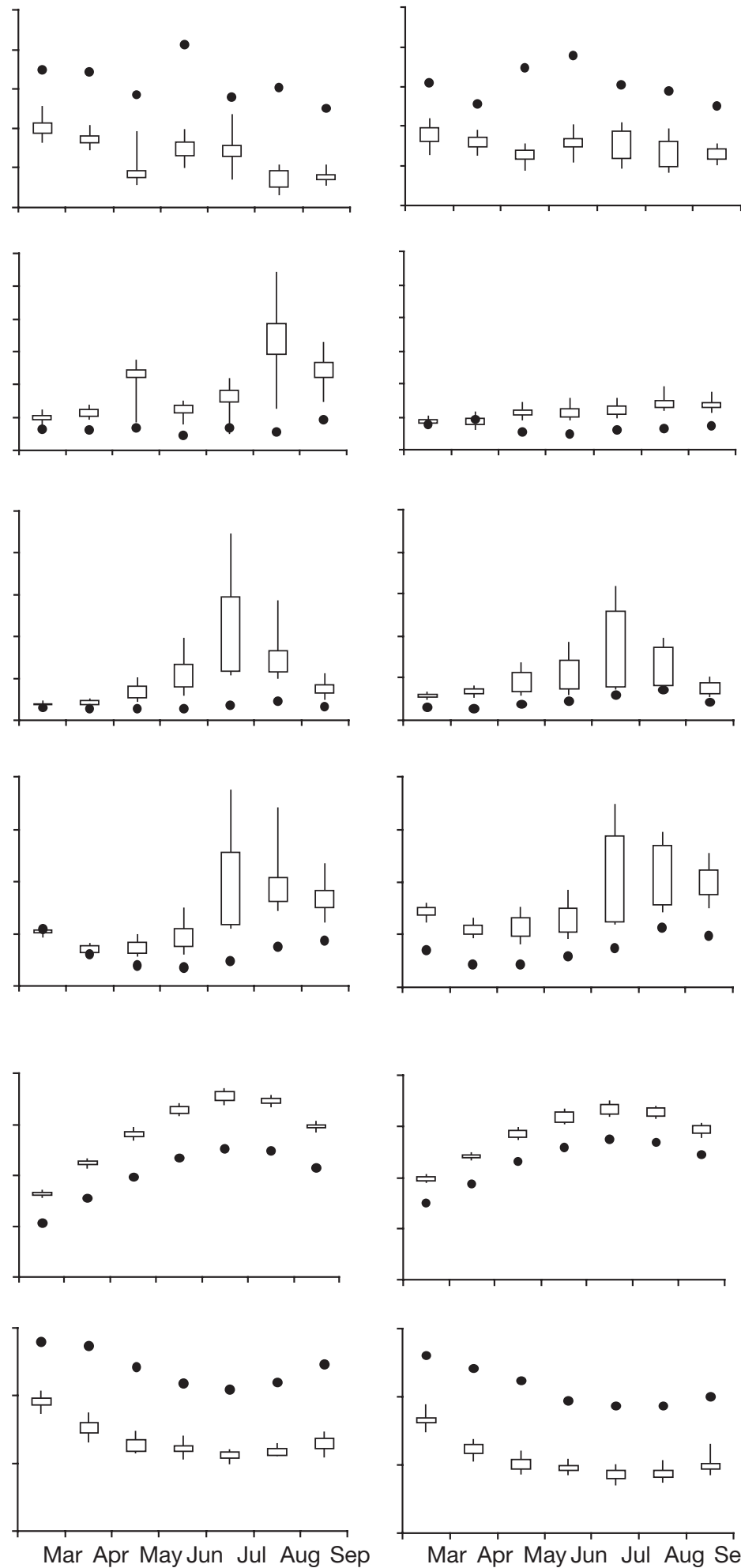

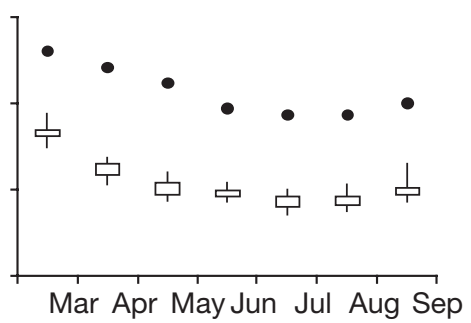

Fig. 1. Monthly variability of the parameters of the 2-parameter Gamma (rainfall), Beta (incoming solar radiation) and Gaussian (Tmax and Tmin combined) distributions for each of the 3 weather stations; fitting the monthly observed parameters at station level $(\bullet)$ and the raw hindcast from the 20 ensemble members (box and whisker plots: 0, 25th, 75th and 100th percentiles). Ensemble members are generated from combinations of 10 different initial atmospheric conditions and 2 convective schemes (see Section 2.2.2). $\alpha$ and $\beta$ : shape and scale parameters of the Gamma distribution (dimensionless) 


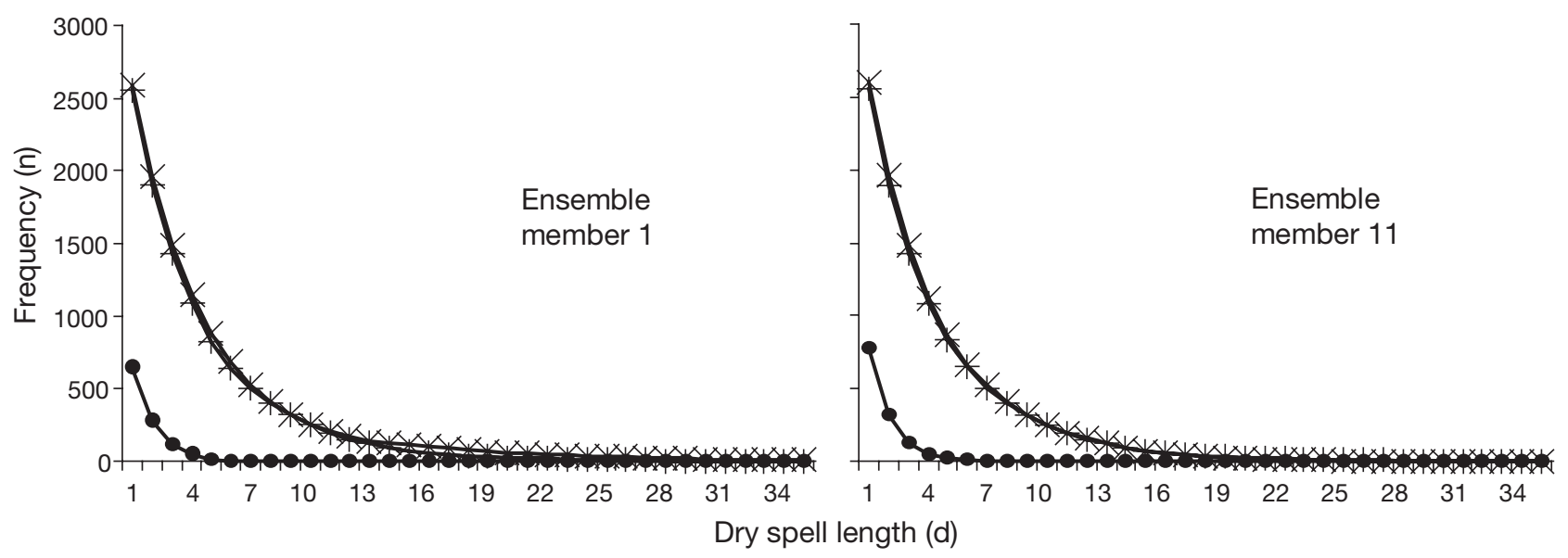

Fig. 2. Dry spell length frequencies among observed $(+)$, raw hindcast $(\bullet)$ and bias-corrected $(\times)$ rainfall data from Gainsville presented for 2 ensemble members. For explanation of ensemble members, see Fig. 1

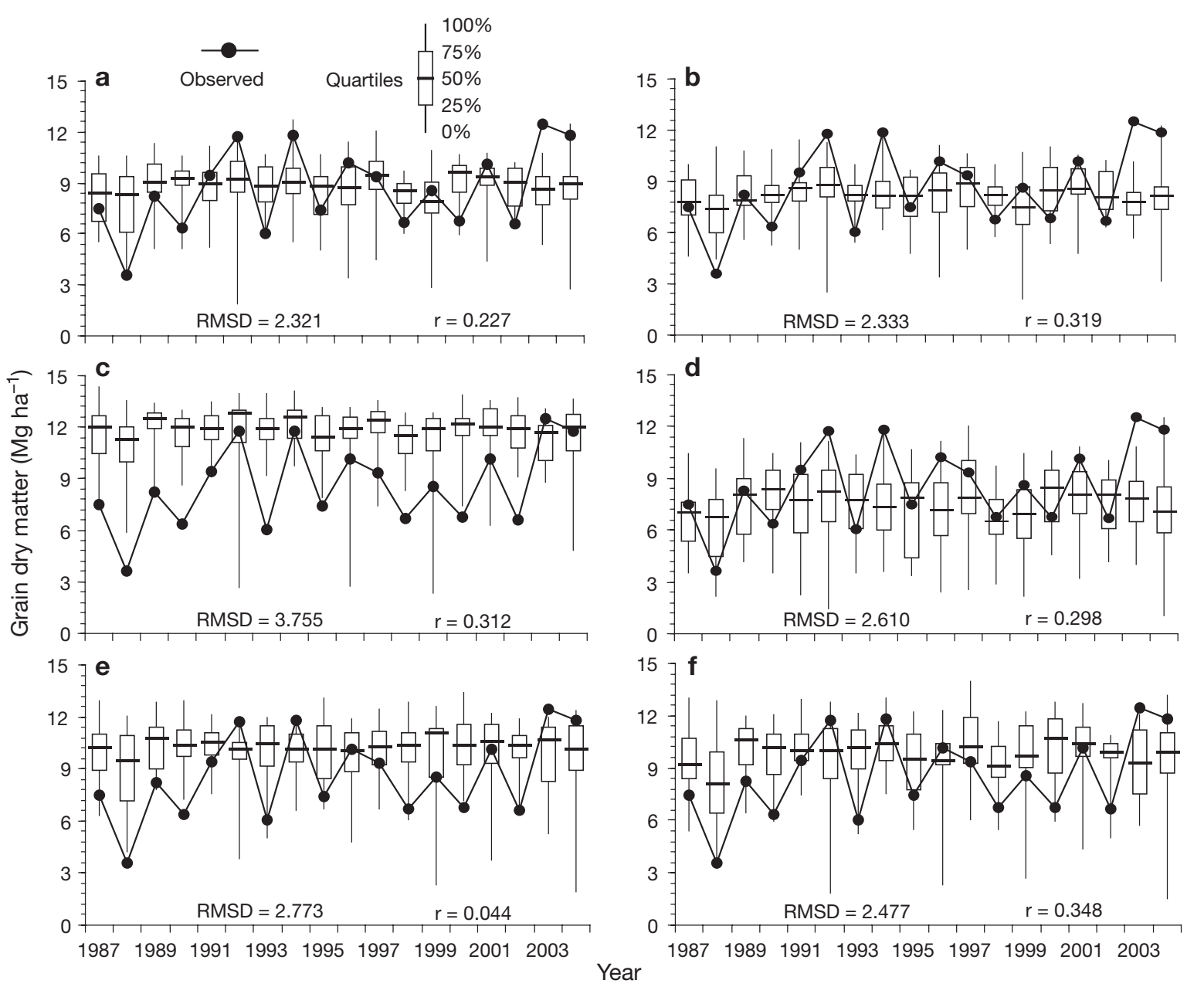

Fig. 3. Simulated corn yield dry matter using observed weather at Crossville (•) and ensemble members' quartiles (box and whisker plots) of: (a) raw hindcast of all variables; (b) bias-corrected hindcast of incoming solar radiation and raw hindcast of the remaining variables; (c) bias-corrected hindcast of Tmax and Tmin and raw hindcast of the remaining variables; (d) biascorrected hindcast of rainfall and raw hindcast of the remaining variables; (e) bias-corrected hindcast of rainfall and climatological monthly average of the remaining variables; and (f) bias-corrected hindcast of all variables. All Pearson correlation values (r) are statistically non-significant $(p=0.05)$. Data represent the study case in which only one place and planting date was used. 
the bias-corrected hindcasts of all variables (Fig. 3f), as well as the effects of each of the bias-corrected individual variables (Fig. 3b-e). The highest Pearson's correlation between the mean of the 20 crop yield ensemble members and the simulated crop yields using observed weather was reached when all the variables were bias-corrected (Fig. 3f). In almost all cases, except Fig. 3e, Pearson's correlations increased in comparison to the baseline (raw hindcast for all variables), although none of the correlations were significant. The lowest value for Pearson's correlation was found when incoming solar radiation and temperatures were replaced by the climatological values (Fig. 3e). The highest RMSD was found when temperatures were bias corrected (Fig. 3c), and those hindcasts showed a large positive bias. The lowest RMSD obtained in this case study was obtained using a raw hindcast in all variables, closely followed by the cases when incoming solar radiation was bias-corrected (Fig. 3b) and when all variables were bias-corrected (Fig. 3f).

Bias correcting Tmax and Tmin increased yield values compared to the raw hindcast of all variables (Fig. 3c \& 3a, respectively). Pearson's correlations and RMSD increased in both cases. As shown in Fig. 1, the FSU/COAPS regional spectral model overestimated temperatures. Bias-correcting Tmax and Tmin decreased these values, thus decreasing the simulated evapotranspiration rates and water stress. In addition, cooler temperatures lengthened the crop growing season. Both of these physiological responses resulted in higher simulated yields for this case.

Bias correction of incoming solar radiation increased Pearson's correlations compared to the raw hindcast of all variables (Fig. 3b \& 3a, respectively).

Comparing crop yield ensembles, none of the convective schemes was more skilful than the others. As explained by Shin et al. (2006), the spatial variability in the predictability skills of the FSU/COAPS regional spectral model was due to the highly nonlinear interaction between the land and the convective schemes.

\subsubsection{Effects of rainfall distribution}

Yields simulated by dynamic crop models were highly sensitive to dry spell sequences during the cropping season. Dubrovský et al. (2000) reported that increasing persistence of wet/dry day occurrence resulted in an increasing probability of drought stress occurrences, which were accompanied by decreased mean and increased variance of the grain yields. According to our results, not only was increasing persistence of wet/dry day occurrence important, but also the timing of those dry spells within the cropping season was especially important. Fig. 4 shows the total and monthly amounts of rainfall during the cropping season, along with corn yields and stress factors affecting growth during the cropping season. The randomly selected location and year in Fig. 4 was Gainesville 1990. As an example, the crop yield Ensemble Member 2 received the maximum amount of rainfall in comparison to other members and to the observed data. However, it showed one of the lowest simulated yields. This was because a long dry spell occurred just before and during tasseling, the most critical period in the production of corn (Irmak et al. 2000). The opposite occurred in crop yield Ensemble Member 6 where the total rainfall amount was in the below-normal tercile, but simulated yields were in the above-normal tercile. In this case, most of the water stress occurred after the grain-filling phase where water did not play an important role in yield.

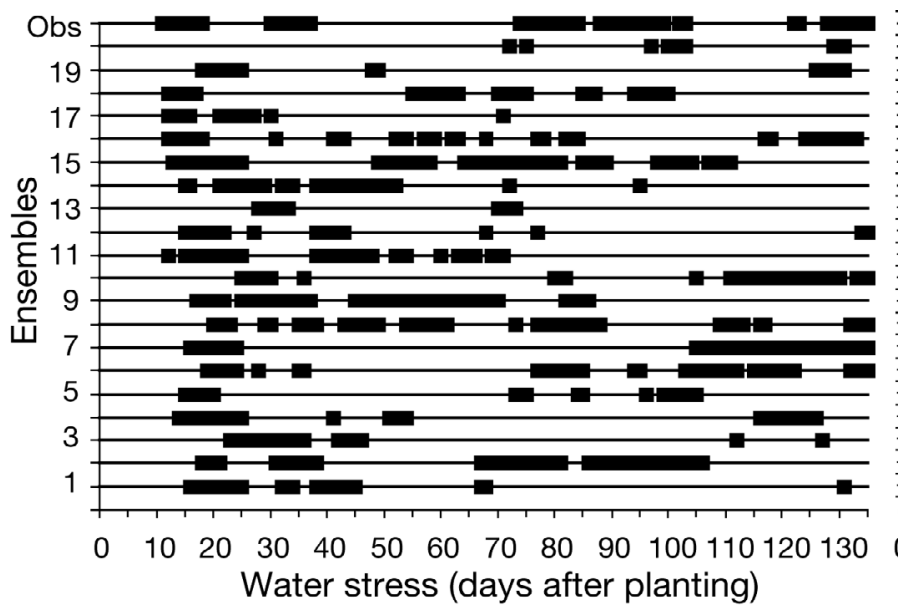

- May

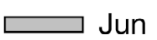

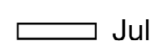
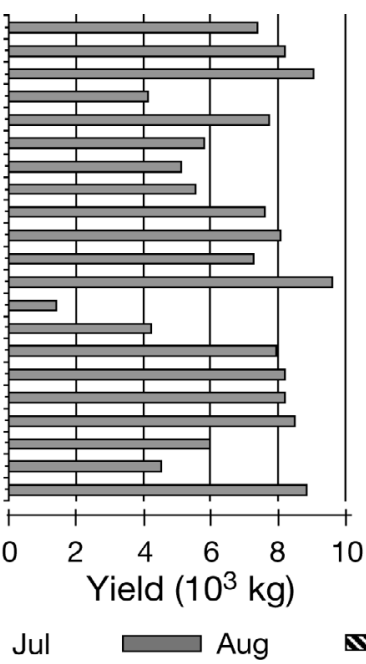

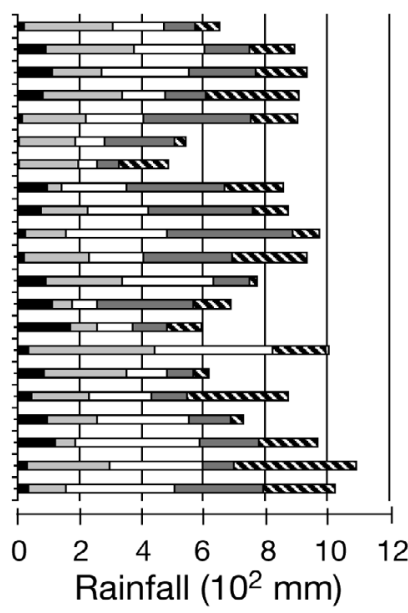

MIII Sep

Fig. 4. Observed (obs) and simulated (ensemble) periods of water stress affecting corn growth and the relationship to dry matter grain yields and total monthly rainfall for Gainesville station, 1990 
Table 2. Root mean squared error $\left(\mathrm{Mg} \mathrm{ha}^{-1}\right)$ between simulated corn yields (dry matter) using observed weather and each bias-corrected hindcast of ensemble members for all variables. $\bar{X}$ : average dry matter from the 7 planting dates

\begin{tabular}{|lcccccc|}
\hline $\begin{array}{l}\text { Planting } \\
\text { dates }\end{array}$ & \multicolumn{2}{c}{ Gainesville } & \multicolumn{2}{c}{ Crossville } & \multicolumn{2}{c|}{ Tifton } \\
& Raw & $\begin{array}{c}\text { Bias- } \\
\text { corrected }\end{array}$ & Raw & $\begin{array}{c}\text { Bias- } \\
\text { corrected }\end{array}$ & Raw & $\begin{array}{c}\text { Bias- } \\
\text { corrected }\end{array}$ \\
\hline March 20 & 5.52 & 2.45 & 2.28 & 2.73 & 4.20 & 1.84 \\
March 30 & 4.77 & 2.46 & 1.94 & 2.52 & 4.11 & 2.02 \\
April 9 & 4.08 & 2.32 & 2.16 & 2.57 & 4.23 & 2.41 \\
April 19 & 3.27 & 2.31 & 2.56 & 2.79 & 4.10 & 2.48 \\
April 29 & 2.86 & 2.11 & 2.31 & 2.48 & 4.12 & 2.84 \\
May 9 & 2.68 & 2.25 & 2.45 & 2.63 & 4.06 & 2.75 \\
May 19 & 2.33 & 2.83 & 2.53 & 2.80 & 3.60 & 2.66 \\
$\bar{X}$ & 3.42 & 1.99 & 2.03 & 2.38 & 3.92 & 2.23 \\
\hline
\end{tabular}

Places with soil textures with higher clay, silt and organic matter contents than the 3 selected locations could be less affected by this problem since more water can be retained in the soil, increasing water availability, and thus reducing the water soil stress factor.

\subsubsection{Simulated crop yield using observed data}

Application of the bias-correction method reduced the RMSD of corn yields for all planting dates in Gainesville and Tifton, but the opposite occurred in Crossville (Table 2). Annual simulated grain dry matter, estimated as the average across different planting dates, also

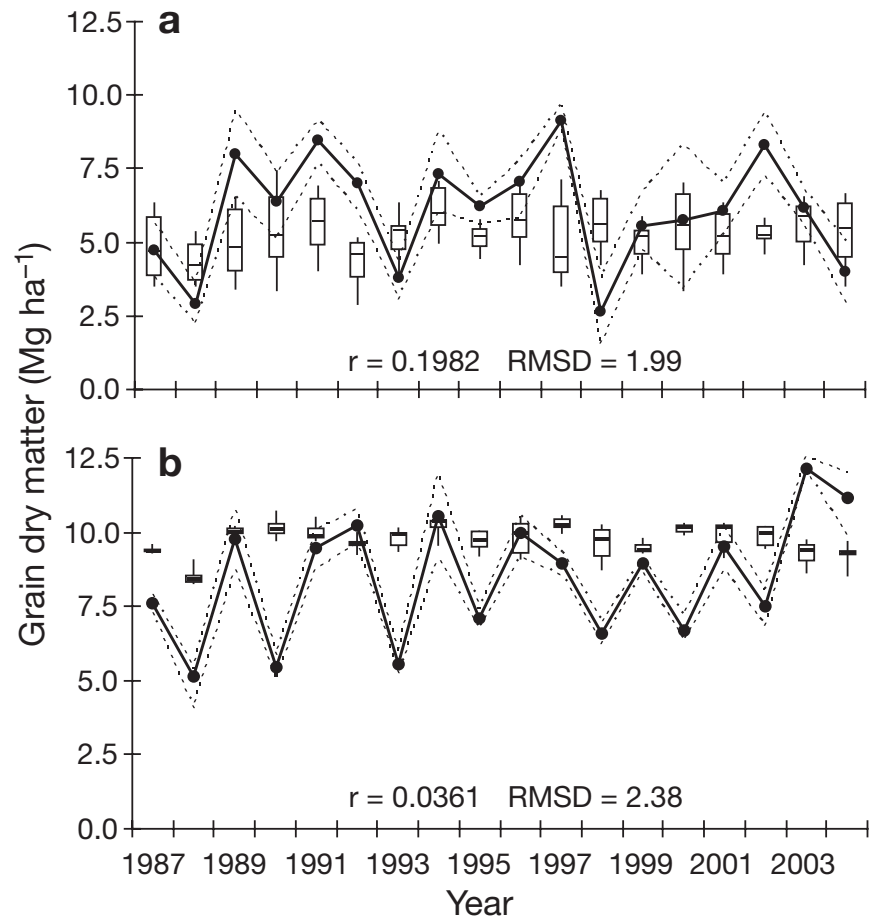

showed a significant reduction in the RMSD in Gainesville and Tifton. In Crossville, the bias-correction method slightly increased the RMSD. Comparisons of the interannual variability of the simulated grain dry matter yields using observed and bias-corrected hindcasted data are presented in Fig. 5. The interannual distribution of mean simulated grain dry matter yield and the first and third quartiles produced using observed weather data were higher than the distribution of the same variable using bias-corrected hindcasted data. These differences were due to averages which were across the 20 crop yield ensemble members and which eliminated extreme realizations.

\section{CONCLUSIONS}

Bias correction applied to the CPF improved the quality of daily and monthly hindcast data provided by the FSU/COAPS regional spectral model for most variables and locations. Dry spell length and frequency were also adequately corrected over the $18 \mathrm{yr}$ hindcasted period by this method; however, as anticipated, timing of rainfall events and dry spells within a growing season were not well simulated or corrected.

There was a large degree of variability among the crop yield ensemble members. Differences in dry spell distribution within the cropping season were the main

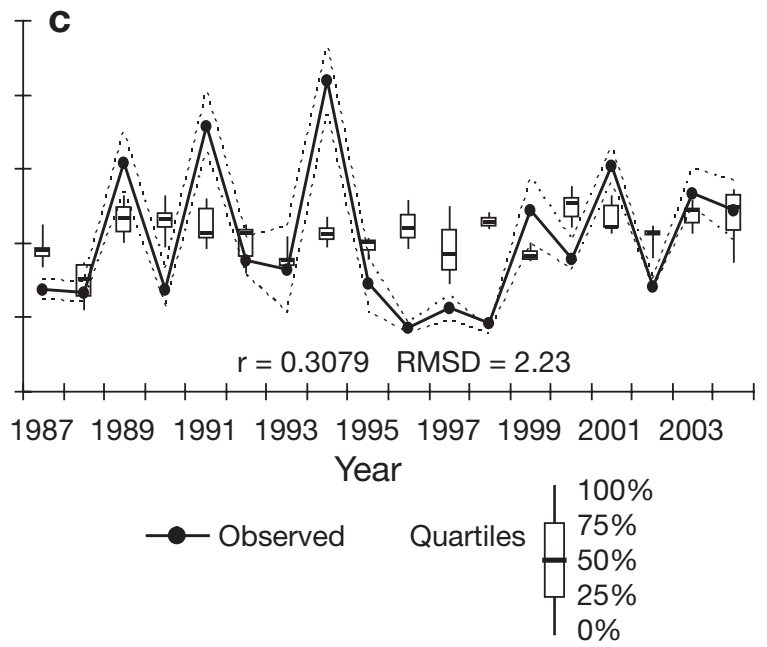

Fig. 5. Simulated grain yield dry matter using observed weather (dots and lines) and hindcasted daily seasonal climate (box and whisker plots) for (a) Gainesville, (b) Crossville and (c) Tifton. (•) Mean, (----) first and third quartile of the 20 ensemble member average across 7 planting dates. None of the Pearson correlation values (r) are statistically significant $(\mathrm{p}=0.05)$ 
source of uncertainty when linking the FSU/COAPS to the CERES-Maize model. A lack of accuracy in predicting the timing of dry spell occurrences combined with a short critical phenological phase window in the crop made the linking process difficult. However, due to improvements, the daily hindcast may be effective when applied to crops that are less sensitive to water stress in a critical growth phase (e.g. pastures, peanut and cotton) in the SE-USA.

Acknowledgements. The study was supported by the National Oceanic and Atmospheric Administration - Applied Research Center (NOAA-ARC) through grant No. NA16GP 1365 subcontract FSU/UF No. 02081352-1-1, and was developed under the auspices of the Southeast Climate Consortium (SECC). The views expressed in this paper are those of the authors and do not necessarily reflect the views of NOAA or any of its sub-agencies.

\section{LITERATURE CITED}

Baigorria GA (2007) Assessing the use of seasonal climate forecasts to support farmers in the Andean Highlands. In: Sivakumar MVK, Hansen JW (eds) Climate prediction and agriculture: advances and challenges. Springer-Verlag, Berlin, p 99-110

Baigorria GA, Jones JW, O'Brien JJ (2007) Understanding rainfall spatial variability in the Southeast USA at different timescales. Int J Climatol 27:749-760

Bonan GB, Oleson KW, Vertenstein M, Levis S, Zeng X, Dai Y, Dickinson RE, Yang ZL (2002) The land surface climatology of the Community Land Model coupled to the NCAR Community Climate Model. J Clim 25:3123-3149

Cantelaube P, Terres JM (2005) Use of seasonal weather forecast in crop yield modelling. Tellus A Dyn Meteorol Oceanogr 57A:476-487

Challinor AJ, Slingo JM, Wheeler TR, Doblas-Reyes F (2005) Probabilistic simulations of crop yield over western India using the DEMETER seasonal hindcast ensembles. Tellus A Dyn Meteorol Oceanogr 57A:498-512

Cocke S, LaRow TE (2000) Seasonal predictions using a regional spectral model embedded within a coupled oceanatmosphere model. Mon Weather Rev 128:689-708

Dubrovský M, Zalud Z, Stastna M (2000) Sensitivity of CERESmaize yields to statistical structure of daily weather series. Clim Change 46:447-472

Fraisse CW, Sudduth KA, Kitchen NR (2001) Calibration of the CERES-Maize model for simulating site-specific crop development and yield on claypan soils. App Eng Agric 17:547-556

Giannini A, Chiang JCH, Cane MA, Kushnir Y, Seager R (2001) ENSO teleconnection to the Tropical Atlantic Ocean: contributions of the remote and local SSTs to rainfall variability in the Tropical Americas. J Clim 14:4530-4544

Goddard L, Mason SJ, Zebiak SE, Ropelewski CF, Basher R, Cane MA (2001) Current approaches to seasonal to interannual climate predictions. Int J Climatol 21:1111-1152

Hansen JW (2002) Realizing the potential benefits of climate prediction to agriculture: issues, approaches, challenges. Agric Syst 74:309-330

Hansen JW, Indeje M (2004) Linking dynamic seasonal climate forecasts with crop simulation for maize yield predic- tion in semi-arid Kenya. Agric For Meteorol 125:143-157 Hansen JW, Jones JW, Kiker CF, Hodges AW (1999) El NiñoSouthern Oscillation impacts on winter vegetable production in Florida. J Clim 12:92-102

Ines AVM, Hansen JW (2006) Bias correction of daily GCM rainfall for crop simulation studies. Agric For Meteorol 138:44-53

Irmak S, Haman DZ, Bastug R (2000) Determination of crop water stress index for irrigation timing and yield estimation of corn. Agron J 92:1221-1227

Jagtap SS, Jones JW, Hildebrand P, Letson D, O'Brien JJ, Podestá G, Zierden D, Zazueta F (2002) Responding to stakeholders' demands for climate information: from research to applications in Florida. Agric Sys 74: 15-430

Jones CA, Kiniry JR (1986) CERES-Maize: a simulation model of maize growth and development. Texas A\&M University Press, College Station, TX

Jones JW, Zur B, Bennett JM (1986) Interactive effects of water and nitrogen stresses on carbon and water vapor exchange of corn canopies. Agric For Meteorol 38: 113-126

Jones JW, Hansen JW, Royce FS, Messina CD (2000) Potential benefits of climate forecasting to agriculture. Agric Ecosyst Environ 82:169-184

Jones JW, Hoogenboom G, Porter $\mathrm{CH}$, Boote KJ and 6 others (2003) The DSSAT cropping system model. Eur J Agron 18:235-265

Mearns LO, Giorgi F, McDaniel L, Shields C (1995) Analysis of daily variability of precipitation in a nested regional climate model: comparison with observations and doubled $\mathrm{CO}_{2}$ results. Global Planet Change 10:55-78

Pan HL, Wu WS (1994) Implementing a mass flux convection parameterization scheme for the NMC Medium Range Forecast Model. Proc 10th Conf on Numerical Weather Prediction, July 1994, Portland, OR. Am Meteorol Soc, p 96-98

Peirce CS (1884) The numerical measure of the success of predictions. Science 4:453-454

Phillips J, Rajagopalan B, Cane M, Rosenzweig C (1999) The role of ENSO in determining climate and maize yield variability in the US corn belt. Int J Climatol 19:877-888

Podestá G, Letson D, Messina C, Royce F and 6 others (2002) Use of ENSO-related climate information in agricultural decision making in Argentina: a pilot experience. Agric Syst 74:371-392

Richardson CW, Wright DA (1984) WGEN: a model for generating daily weather variables. Publication ARS-8, US Department of Agriculture, Washington, DC

Rosmond TE (1992) The design and testing of the Navy Operational Global Atmospheric Prediction System. Weather Forecasting 7:262-272

Sadras VO, Calviño PA (2001) Quantification of grain yield response to soil depth in soybean, maize, sunflower, and wheat. Agron J 93:577-583

Saravanan R, Chang P (2000) Interaction between Tropical Atlantic variability and El Niño-Southern Oscillation. J Clim 13:2177-2194

Shin DW, LaRow TE, Cocke S (2003) Convective scheme and resolution impacts on seasonal precipitation forecasts. Geophys Res Lett 30:2078

Shin DW, Cocke S, LaRow TE, O'Brien JJ (2005) Seasonal surface air temperature and precipitation in the FSU Climate Model coupled to the CLM2. J Clim 18:3217-3228

Shin DW, Below JG, LaRow TE, Cocke S, O'Brien JJ (2006) The role of an advance land model in seasonal dynamical downscaling for crop model application. J Appl Meteorol Climatol 45:686-701

SRAT (Southeast Regional Assessment Team) (2002) Prepar- 
ing for a changing climate: the potential consequences of climate variability and change - Southeast. U.S. Global Change Program, Huntsville, AL

Steele DD, Stegman EC, Knighton RE (2000) Irrigation management for corn in the northern Great Plains, USA. Irrig Sci 19:107-114
USGS (United States Geological Survey) (2006) Status and trends of our living resources. Available at: http://biology. usgs.gov/status_trends/

Wilks DS (2006) Statistical methods in the atmospheric sciences. International Geophysics series, 2nd edn. Elsevier Academic, San Diego, CA

Appendix 1. Description of the bias-correction method applied to incoming solar radiation and Tmax and Tmin

\section{Bias-correction of incoming solar radiation}

The probability density function for the Beta distribution can be written as (Wilks 2006):

$f(x ; p, q)=\left[\frac{\Gamma(\mathrm{p}+\mathrm{q})}{\Gamma(p) \Gamma(q)}\right] x^{p-1}(1-x)^{q-1} ; \quad 0 \leq x \leq 1, p, q>0$

See Table 1 for definitions of variables. The Beta distribution parameters were fitted using the method of moments and thus, the moment estimators were calculated using:

$$
\hat{p}=\frac{\bar{x}^{2}(1-\bar{x})}{s^{2}}-\bar{x} ; \quad \hat{q}=\frac{\hat{p}(1-\bar{x})}{\bar{x}}
$$

where $\hat{p}$ and $\hat{q}$ are the moment estimators (dimensionless) of $p$ and $q$. Because values of incoming solar radiation ranged from 0 to $33 \mathrm{MJ} \mathrm{m}^{-2} \mathrm{~d}^{-1}$, and the Beta distribution is limited to the interval $[0,1]$, a transformation is needed before its application by using:

$$
\bar{X}^{\prime}=\frac{\bar{x}-a}{b-a} ; \quad s_{X^{\prime}}^{2}=\frac{s_{X}^{2}}{(b-a)^{2}}
$$

$\Gamma(\lambda)$ is defined as the gamma function, and is estimated by:

$$
\Gamma(\lambda)=\int_{z=0}^{\infty} z^{\lambda-1} \mathrm{e}^{-z} \mathrm{~d} z
$$

The inverse of the Beta cumulative distribution was used to solve for specific $x$ values by an iterative search technique. After the bias-correction was applied, values of in- coming solar radiation were checked to avoid values out of an appropriate range. Low values of incoming solar radiation are usually related to short day lengths, and generally occur in high latitudes and are related to cloudy conditions. For instance, the lowest value of daily incoming solar radiation $\left(0 \mathrm{MJ} \mathrm{m}^{-2} \mathrm{~d}^{-1}\right)$ was reached only during wintertime in latitudes higher than $66^{\circ} 33^{\prime}$ (polar circles) where day length $=0$. Therefore, bias-corrected values with $<20 \%$ of the extraterrestrial radiation $(<0.1 \%$ of the data) were replaced by this $20 \%$. This threshold was established by taking the measured observation of 2 automatic weather stations networks operating in the study area (http://fawn.ifas.ufl.edu and www.georgiaweather.net) into consideration.

\section{Bias-correction of Tmax and Tmin}

The probability density function for the Gaussian distribution can be written as (Wilks 2006):

$$
f(x ; \bar{x}, s)=\frac{1}{s \sqrt{2 \pi}} \mathrm{e}^{-\frac{(x-\bar{x})^{2}}{2 s^{2}}} ;-\infty \leq x \leq \infty
$$

Applying bias-correction to Tmin and to Tmax separately can generate values of Tmin larger than Tmax (G. A. Baigorria pers. obs.). To avoid this, data from both variables were combined before fitting the Gaussian distribution.

The inverse of the Gaussian cumulative distribution was used to solve for specific $x$ values by an iterative search technique. 